\title{
Increased expression of collagenase-3 (MMP-13) and MT1-MMP in oesophageal cancer is related to cancer aggressiveness
}

\author{
T Etoh, H Inoue, Y Yoshikawa, G F Barnard, S Kitano, M Mori
}

Department of Surgery, Medical Institute of

Bioregulation, Kyushu University, Beppu, Japan

T Etoh

$\mathrm{H}$ Inoue

M Mori

Department of Pathology, Medical

Institute of

Bioregulation, Kyushu

University, Beppu,

Japan

Y Yoshikawa

Division of Digestive Disease and Nutrition, University of

Massachusetts Medical

Center, Worcester,

Massachusetts, USA

G F Barnard

Department of Surgery I, Faculty of Medicine, Oita

Medical University, Oita, Japan

S Kitano

Correspondence to: Dr M Mori, Department of Surgery, Medical Institute of Bioregulation, Kyushu

University, 4546

Tsurumihara, Beppu

874-0838, Japan.

Email:mmori@

tsurumi.beppu.kyushu-u.ac.jp

Accepted for publication

5 November 1999

\begin{abstract}
Background-Collagenase-3 (matrix metalloproteinase-13, MMP-13) is a recently identified human MMP with broad substrate specificity which can be activated by membrane type 1 (MT1) matrix metalloproteinase in vitro. These may play a critical role in cancer aggressiveness.

Aims-To examine the clinical significance of collagenase -3 expression and the cooperative role of MT1-MMP in human oesophageal carcinomas.
\end{abstract}

Patients-Forty five individuals with oesophageal carcinoma who underwent surgery without preoperative treatment.

Methods-The tumour/normal (T/N) ratios of collagenase-3 and MT1-MMP mRNA expression in 45 human oesophageal carcinomas were determined by northern blot analysis. The production and localisation of collagenase-3 and MT1-MMP proteins were investigated by immunohistochemistry, western blot analysis, and zymography.

Results-The mean $T / N$ ratio of collagenase- 3 mRNA was 3.5 and that of MT1-MMP 2.1. There was a significant correlation between collagenase- 3 and MT1-MMP mRNA expression $(\mathrm{p}<0.001)$. Twenty two cases with a collagenase- $3 \mathrm{~T} / \mathrm{N}$ ratio $>3.5$ showed a significantly higher frequency of vascular involvement and lymph node metastasis, and tended to be at a more advanced stage than 23 cases with a $T / N$ ratio $\leqslant 3.5(p<0.05)$. Western blot analysis and zymography demonstrated production of collagenase- 3 protein in tumour tissues but not in normal tissues. Immunohistochemical studies revealed that collagenase- 3 was localised predominantly in tumour cells and MT1MMP was detected in the same collagenase- 3 positive cells; there was a significant association between collagenase-3 and MT1-MMP protein expression $(\mathrm{p}<0.05)$. With regard to prognosis, the survival time for subjects in the high collagenase- 3 group $(T / N$ ratio $>3.5)$ was significantly worse $(\mathrm{p}<0.05)$.

Conclusions-These data suggest that production of collagenase- 3 together with MT1-MMP is implicated in tumour aggressiveness and prognosis in human oesophageal carcinomas.

(Gut 2000;47:50-56)

Keywords: collagenase-3; MT1-MMP; oesophageal carcinoma; cancer aggressiveness; prognosis
Oesophageal carcinoma is one of the most aggressive tumours and its growth is relatively rapid. In particular, the presence of lymph node metastasis and vascular invasion indicate a highly malignant potential in oesophageal carcinoma. ${ }^{1}$ In general, patients with oesophageal carcinoma have a poorer prognosis than those with other gastrointestinal tumours unless intensive therapy is given (radical surgery, chemotherapy, and radiotherapy). The five year survival is $20-30 \%$ after curative surgery. ${ }^{2}$ The reason for this poor prognosis is that oesophageal cancer exhibits extensive local invasion or frequent regional lymph node metastasis, even at the time of initial diagnosis. Tumour invasion and metastasis involve degradation of different components of the extracellular matrix and require the actions of proteolytic enzymes, such as matrix metalloproteinases (MMPs), produced either by the tumour cells themselves or by surrounding stromal cells. It therefore seems evident that MMPs play an important role in tumour invasion and metastasis. ${ }^{3-6}$

Members of the collagenase subfamily, interstitial collagenase (MMP-1), neutrophil collagenase (MMP-8), and collagenase-3 (MMP-13) are the principal neutral proteinases capable of cleaving native fibrillar collagens in the extracellular space, and they apparently play a key role in degradation of the collagen matrix. ${ }^{78}$ Human collagenase-3 (MMP-13), which represents the third member of the collagenase subfamily, has been recently identified in human breast carcinomas and in osteoarthritic cartilage. ${ }^{9}$ Expression of collagenase- 3 has been detected in squamous cell carcinomas of the head and neck, ${ }^{10}$ chondrosarcoma, ${ }^{11}$ oral mucosal epithelium of chronic inflammation, ${ }^{12}$ rheumatoid synovium, and developing bone, ${ }^{13}{ }^{14}$ but not in normal adult tissues. The substrate specificity of collagenase- 3 is similar to that of the gelatinases and, unlike interstitial and neutrophil collagenases (MMP-1 and MMP-8), this enzyme degrades several fibrillar collagens. As collagenase- 3 widely degrades components of the basement membrane and connective tissue surrounding tumour cells, this collagenase is likely to play crucial roles in modulating extra-

Abbreviations used in this paper: MMP, matrix metalloproteinase; MT1-MMP, membrane type 1 matrix metalloproteinase; GAPDH, glyceraldehyde-3-phosphate dehydrogenase; T/N, tumour/normal; TBS, Tris buffered saline; SDS, sodium dodecyl sulphate; PAGE, polyacrylamide gel electrophoresis; CI, confidence intervals; EMR, endoscopic mucosal resection. 
cellular matrix degradation and the cell-matrix interactions involved in metastasis.

It has been demonstrated under physiological and pathophysiological conditions that activation of procollagenase- 3 can be regulated by membrane type 1 matrix metalloproteinase (MT1-MMP) acting as a cell surface activator of progelatinase A (proMMP2). ${ }^{15}$ Some investigations link expression of MT1-MMP, which is over expressed in various tumour tissues, and gelatinase subfamilies, separately or in combination, to invasive and metastatic aggressiveness and prognosis. ${ }^{17-20}$ In oesophageal carcinoma, several MMPs that are closely associated with the malignant potential of tumour cells have been identified, including collagenase (MMP-1), gelatinases (MMP-2 and MMP-9), and stromelysin (MMP-3). ${ }^{21-23}$ However, documentation related to the clinical significance of collagenase-3 (MMP-13) expression and the correlation between collagenase-3 and MT1-MMP expression in oesophageal carcinoma has not been forthcoming.

In this present study, on the basis of in vitro data, ${ }^{1516}$ we have investigated gene expression, production levels, and tissue localisation of collagenase- 3 and its activator MT1-MMP in human oesophageal carcinoma tissues and studied whether collagenase- 3 plays an important role in tumour aggressiveness in association with MT1-MMP.

\section{Materials and methods}

CLINICAL SPECIMENS

From 1992 to 1998,175 patients with primary oesophageal carcinomas were admitted to the Department of Surgery, Medical Institute of Bioregulation, Kyushu University (Beppu, Japan) (25 patients) or the Department of Surgery, Saitama Cancer Center (Saitama, Japan) (150 patients). Among these, 135 patients underwent oesophagectomy. The remaining 40 patients were not surgically treated; 13 patients had tumours that were not resectable and another 27 patients had endoscopic mucosal resection (EMR). Fresh surgical specimens were obtained from the 45 patients who had undergone surgical treatment and their paired adjacent normal oesophageal mucosa. There were 40 male and five female patients (mean age 63.9 (SD 8.5) years, range $40-82$ ). None had received preoperative treatments such as radiation or chemotherapy.

Data on patient outcome, including overall survival and development of metastases, were available for all 45 patients, and the observation periods ranged from two to 72 months (median follow up period 36.2 months). Of the 45 patients, 17 died from recurrence of disease. Immediately after resection, the necrotic and ulcerated parts of the tumour were removed, and normal oesophageal mucosa was dissociated from the muscle and connective tissue. All tissue specimens were then frozen in liquid nitrogen and kept at $-90^{\circ} \mathrm{C}$ until analysis. The specimens were prepared for RNA extraction. To avoid contamination by genomic DNA, 50 $\mu \mathrm{g}$ of total RNA was treated with 1 unit of DNase 1 (Message clean kit, Gen Hunter
Corp.) at $37^{\circ} \mathrm{C}$ for one hour in the presence of 1 unit of RNase inhibitor, followed by phenol/ chloroform purification and ethanol precipitation. The treated RNA was stored at $-90^{\circ} \mathrm{C}$. Whenever possible, specimens were also prepared for immunohistochemical studies, sodium dodecyl sulphate-polyacrylamide gel electrophoresis (SDS-PAGE), and gelatin zymography analysis (see below).

\section{NORTHERN BLOT ANALYSIS}

Total cellular RNA was isolated from surgical specimens, electrophoresed in formaldehydeagarose gels and transferred to Hybond $\mathrm{N}$ nylon filters (Amersham International). Filters containing $15 \mu \mathrm{g}$ of total RNA per sample were prehybridised at $42^{\circ} \mathrm{C}$ for one hour in $50 \%$ formamide, $5 \times$ SSPE $(1 \times$ SSPE contains 150 $\mathrm{mM}, 10 \mathrm{mM} \mathrm{NaH} \mathrm{PO}_{4}, 1 \mathrm{mM}$ EDTA, pH 7.4), $10 \times$ Denhardt's, $2 \times$ SDS, and $100 \mu \mathrm{g} / \mathrm{ml}$ of denatured herring sperm DNA and then hybridised with [alpha ${ }^{32} \mathrm{P}$ ] labelled by random priming full length cDNA probes for either collagenase-3 or MT1-MMP for 24 hours under the same conditions. Filters were washed with $0.2 \times$ SSC and $0.5 \%$ SDS for at least 30 minutes at $65^{\circ} \mathrm{C}$, exposed to autoradiography for two hours and the mRNA levels quantitated using a Bio-Image analyser BAS 1000. mRNA expression in tumour (T) and normal (N) tissues in each pair was estimated on the basis of the counts obtained. RNA integrity and equal loading were assessed by hybridisation with glyceraldehyde-3-phosphate dehydrogenase (GAPDH). The tumour/normal ratio ( $\mathrm{T} / \mathrm{N}$ ratio) of collagenase-3 and MT1-MMP expression was calculated after correction for GAPDH expression. Furthermore, we confirmed the reproducibility of the experiments at least three times.

WESTERN BLOT ANALYSIS

Surgical specimens were rinsed twice with PBS at $4^{\circ} \mathrm{C}$ and lysed with cold Triton lysis buffer (50 mM Tris/ $\mathrm{HCl}, \mathrm{pH} 7.5,1 \mathrm{mM} \mathrm{Na} \mathrm{P}_{2} \mathrm{O}_{7}, 1 \%$ Triton-X 100, 2 mM EGTA, 2 mM EDTA$\mathrm{Na})$ containing protease inhibitors ( $1 \mathrm{mM}$ phenylmethylsulphonyl fluoride, $3.5 \mathrm{mg} / \mathrm{ml}$ pepstatin A, $25 \mathrm{mg} / \mathrm{ml}$ leupeptin, $25 \mathrm{mg} / \mathrm{ml}$ aprotinin) for 30 minutes. After incubation, cell lysates containing protein were collected by centrifugation $\left(4000 \mathrm{rpm}\right.$ at $4^{\circ} \mathrm{C}$ for 15 minutes). Each aliquot containing $100 \mu \mathrm{g}$ of total protein was fractionated on $12 \%$ SDSPAGE and transferred to Trans-Blot Transfer Medium nitrocellulose membranes (Bio-Rad, Richmond, California, USA). The membranes were blocked for two hours at room temperature in $10 \%(\mathrm{w} / \mathrm{v})$ milk powder in Tris buffered saline (TBS). The membranes were then incubated overnight with monoclonal antibody 181-15A11 which specifically recognises human collagenase-3, and monoclonal antibody 114-6G6 which specifically recognises human MT1-MMP (Fuji Chemical Industries, Takaoka, Japan), both diluted 1:1000 in TBS at $4^{\circ} \mathrm{C}$. The membranes were washed twice for 15 minutes with $0.1 \%$ tween/TBS and incubated with a horseradish-peroxidase conjugated goat antiserum against mouse IgG, diluted 1:1000 
in TBS. Finally, the bound antibodies were detected using an enhanced chemiluminescence detection system (Amersham, Little Chalfont, UK).

GELATIN ZYMOGRAPHY

SDS-PAGE and zymography, using gelatin containing gel to detect gelatinolytic activities, were performed for 24 cases following previously reported procedures. ${ }^{5}$ Briefly, each surgical specimen was homogenised in sample buffer containing $10 \mathrm{mM}$ Tris/ $\mathrm{HCl}, \mathrm{pH}$ 6.8, $20 \%$ glycerin, $2 \%$ SDS, and $0.1 \%$ bromophenol blue. Samples were separated by electrophoresis on a $10 \%$ polyacrylamide gel containing $0.1 \%$ SDS and $1 \mathrm{mg} / \mathrm{ml}$ gelatin as substrate. Gels were then washed in renaturation buffer $(50 \mathrm{mM}$ Tris/ $\mathrm{HCl}, \mathrm{pH} 7.5,0.1 \mathrm{M}$ $\mathrm{NaCl}$ ) containing 2.5\% Triton-X 100 for 90 minutes. Thereafter the gels were incubated for 18 hours at $37^{\circ} \mathrm{C}$ in reaction buffer $(50 \mathrm{mM}$ Tris/ $\mathrm{HCl}, \mathrm{pH} 7.5,10 \mathrm{mM} \mathrm{CaCl}$ ) and stained with $0.1 \%$ Coomassie brilliant blue R250. The collagenase- 3 band was detected at $58 \mathrm{kDa}$ (other bands are discussed in the text). The gels were photographed using a digital camera, and the negatively stained gelatinolytic bands were analysed by optical densitometry.

IMMUNOHISTOCHEMISTRY

To identify the localisation of collagenase- 3 and MT1-MMP in the oesophageal cancer tissue specimens, immunohistochemical analysis was performed for 35 cases as described previously. ${ }^{24}$ After $5 \mu \mathrm{m}$ thick sections were cut from an AMeX fixed, paraffin embedded block, endogenous peroxidase and non-specific binding were blocked by sequential incubation of the sections in $10 \%$ hydrogen peroxidase solution and in bovine serum albumin. Incubation with antiserum against each recombinant human collagenase- 3 or MT1-MMP (diluted $1: 1000$ in TBS, pH 7.2) was performed at $4^{\circ} \mathrm{C}$ for 16 hours. The collagenase- 3 and MT1MMP protein were detected using the avidinbiotin peroxidase method (LSAB Kit; DAKO, Kyoto, Japan). ${ }^{25}$ The sections were finally counterstained with Meyer's haematoxylin.

The intensity of collagenase- 3 and MT1MMP staining was considered positive when unequivocal staining was seen in cells, regardless of the number of cells stained.

STATISTICAL ANALYSIS

The BMDP Statistical Package program (BMDP, Los Angeles, California, USA) for the main frame computer (4381; IBM, Armonk, New York, USA) was used for all analyses. Associations between the variables were tested by Student's $t$ test or Fisher's exact probability test. A linear regression analysis was performed to test the relationship between collagenase-3 and MT1-MMP. The BMDP PIL program was used for survival analysis (Kaplan-Meier method) and for testing the equality of the survival curves (Mantel-Cox method). The BMDP P2L program was used for multivariate adjustments for some covariates, simultaneously with Cox's proportional hazards model. Model selection was performed using a for- ward stepwise method. Statistical differences were considered significant at $\mathrm{p}<0.05$.

The histopathological type and staging of oesophageal carcinomas were classified based on the criteria set up by the Japanese Society of Esophageal Diseases. ${ }^{26}$

\section{Results}

MRNA EXPRESSION OF COLLAGENASE-3 (MMP-13) DETERMINED BY NORTHERN BLOT ANALYSIS AND ITS CLINICAL SIGNIFICANCE

Northern blot analysis, which measures steady state mRNA levels, showed variable levels of collagenase- 3 mRNA signals in oesophageal carcinomas. The $\mathrm{T} / \mathrm{N}$ ratio of collagenase- 3 mRNA, corrected for GAPDH mRNA, ranged from 0.5 to 26.8 (mean 3.5) and exceeded 1.0 in 39 cases $(86.7 \%)$. In the same manner, the $\mathrm{T} / \mathrm{N}$ ratio of MT1-MMP mRNA ranged from 0.3 to 13.5 (mean 2.1) and exceeded 1.0 in 35 cases $(77.8 \%)$. Figure 1 shows five representative cases. In tumour tissues, intense bands were detected while no band was present in normal tissues. Two intense bands (approximately 2.0 and $2.5 \mathrm{~kb}$ ) present in the signals corresponding to the RNA of collagenase- 3 could be the result of utilisation of different polyadenylation sites. ${ }^{9}$

In practical evaluations it is desirable to establish a cut off value for the $\mathrm{T} / \mathrm{N}$ ratio to estimate the malignant potential of each case. We therefore set several cut off values arbitrarily to select the best one. T/N ratios of collagenase- 3 mRNA expression of 3.0, 3.3, $3.5,3.7$, and 4.0 were evaluated. When 3.5 (mean) was used as a cut off value, significant differences were found with respect to vascular involvement, lymph node metastasis, and stage of disease. The number of patients whose $\mathrm{T} / \mathrm{N}$ ratio was $\leqslant 3.5$ was 23 , with 22 patients with a $\mathrm{T} / \mathrm{N}$ ratio $>3.5$, giving two well balanced groups. We therefore selected 3.5 as the most appropriate cut off value. When 2.1 (mean) was used as a cut off $\mathrm{T} / \mathrm{N}$ value with regard to MT1-MMP, the groups were balanced: 24 patients had a $\mathrm{T} / \mathrm{N}$ ratio $\leqslant 2.1$ and 21 a $\mathrm{T} / \mathrm{N}$ ratio $>2.1$.

As shown in table 1 , the 22 patients with collagenase- 3 mRNA expression with a T/N ratio $>3.5$ showed a significant difference in

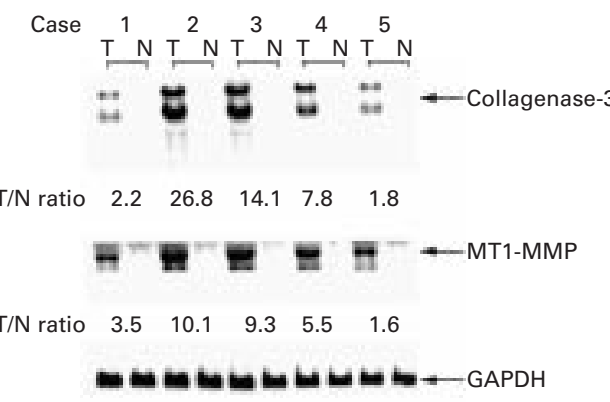

Figure 1 Total RNA isolated from the surgical specimens was analysed by northern blot hybridisation using a $c D N A$ probe specific for human collagenase-3 (MMP-13), membrane type 1 matrix metalloproteinase (MT1-MMP), and glyceraldehyde-3-phosphate dehydrogenase (GAPDH). Two intense bands (approximately 2.0 and 2.5 $k b$, respectively), present in the lanes probed for the $R N A$ of collagenase- 3 could be the result of utilisation of different polyadenylation sites. T/N ratio, tumour/normal ratio. 
Table 1 Clinicopathological features and relative expression of collagenase-3 $m R N A$ in oesophageal carcinomas

\begin{tabular}{|c|c|c|c|}
\hline \multirow[b]{2}{*}{ Variable } & \multicolumn{2}{|c|}{ Relative expression of collagenase- $3 \mathrm{mRNA}$} & \multirow[b]{2}{*}{ p Valu } \\
\hline & $T / N \leqslant 3.5(n=23)$ & $T / N>3.5(n=22)$ & \\
\hline Age & $64.4(10.7)$ & $63.0(8.7)$ & NS \\
\hline \multicolumn{4}{|l|}{ Sex } \\
\hline Male & 19 & 21 & NS \\
\hline Female & 4 & 1 & \\
\hline \multicolumn{4}{|l|}{ Location } \\
\hline Upper & 1 & 1 & NS \\
\hline Middle & 12 & 17 & \\
\hline Lower & 10 & 4 & \\
\hline Histology & & & NS \\
\hline Well diff. scc & 5 & 4 & \\
\hline Moderately diff. scc & 11 & 12 & \\
\hline Poorly diff. scc & 6 & 6 & \\
\hline Others & 1 & 0 & \\
\hline Depth & & & NS \\
\hline No invasion to the adventitia & 7 & 4 & \\
\hline Invasion to the adventitia & 16 & 18 & \\
\hline Lymphatic involvement & & & NS \\
\hline Negative & 3 & 2 & \\
\hline Positive & 20 & 20 & \\
\hline Vascular involvement & & & $<0.05$ \\
\hline Negative & 1 & 5 & \\
\hline Positive & 22 & 17 & \\
\hline Lymph node metastasis & & & $<0.05$ \\
\hline Negative & 2 & 12 & \\
\hline Positive & 21 & 10 & \\
\hline \multicolumn{4}{|l|}{ Stage } \\
\hline $1+2$ & 0 & 4 & $<0.05$ \\
\hline $3+4$ & 23 & 18 & \\
\hline
\end{tabular}

$\mathrm{T} / \mathrm{N}$, tumor/normal; diff. scc, differentiated squamous cell carcinoma. NS, not significant. vascular involvement, lymph node metastasis, and advanced stage compared with the 23 patients with a $\mathrm{T} / \mathrm{N}$ ratio $\leqslant 3.5$. In contrast, there was no significant correlation between levels of MT1-MMP mRNA and clinicopathological features (data not shown).

The $\mathrm{T} / \mathrm{N}$ ratio of collagenase- 3 and the corresponding MT1-MMP mRNA expression determined by northern blot analysis were plotted in each case. As shown in fig 2, the correlation was significant $(\mathrm{p}<0.001)$.

EXPRESSION OF COLLAGENASE-3 IN TUMOUR AND NORMAL TISSUES BY GELATIN ZYMOGRAPHY AND WESTERN BLOT ANALYSIS

To further evaluate the role of collagenase- 3 in oesophageal carcinoma, we studied 24 tumour samples from patients with various stages of

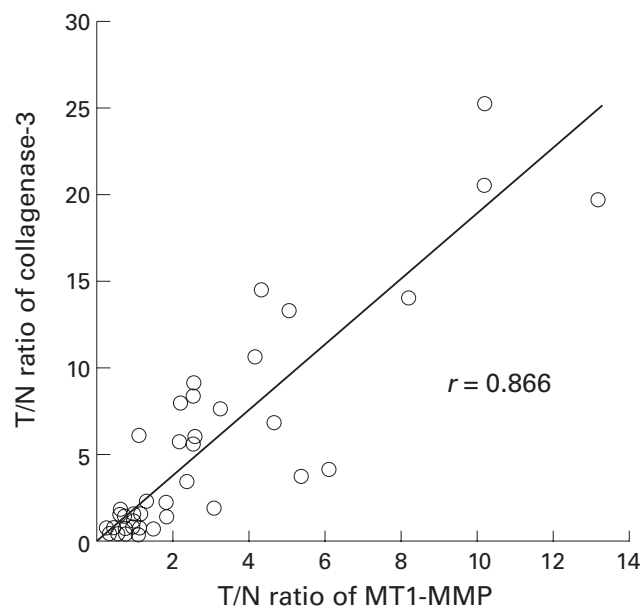

Figure 2 Plots of the tumour/normal ratio (T/N ratio) of collagenase-3 and the corresponding $T / N$ ratio of membrane type 1 matrix metalloproteinase (MT1-MMP) for each case, showing a significant correlation $(p<0.001)$.

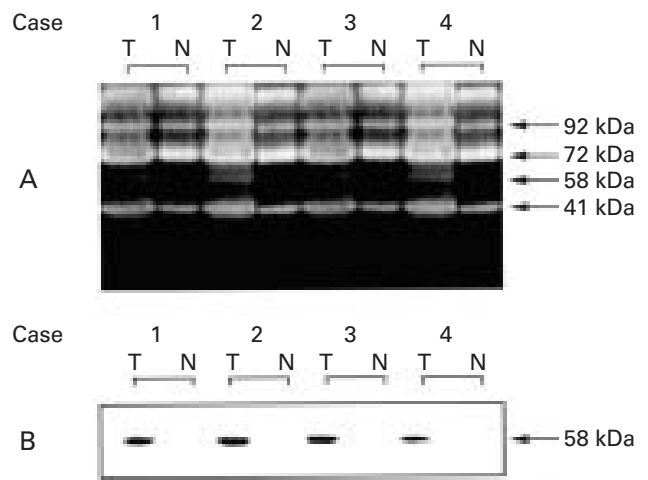

Figure 3 Protein isolated from the surgical specimens was analysed by gelatin zymography $(A)$ and by western blot using specific collagenase-3 antibody (B), as described in the results section. T, tumour; $N$ normal.

oesophageal cancer. Zymographic analysis for tumour specimens revealed three strong gelatinolytic bands with molecular weights of $92 \mathrm{kDa}$ (MMP-9), $72 \mathrm{kDa}$ (latent form of MMP-2), and $41 \mathrm{kDa}$ (activated form of MMP-2) whereas these bands in normal tissues were weak. In addition, the analysis revealed the presence of a $58 \mathrm{kDa}$ band in all tumour tissues compared with normal specimens (fig 3A). The molecular weight of this gelatinolytic band corresponded to that of human collagenase-3. Western blot analysis using antibody specific for human collagenase- 3 showed that $58 \mathrm{kDa}$ collagenase- 3 was present in all tumour tissues but not in normal tissues, and correlated well with levels of the $58 \mathrm{kDa}$ gelatinolytic proteinase in the same samples (fig 3B). A total of 18 of the 22 patients $(81.8 \%)$ with collagenase- 3 mRNA expression with a $\mathrm{T} / \mathrm{N}$ ratio $>3.5$ had a gelatinolytic band corresponding to human collagenase-3.

COLLAGENASE-3 AND MT1-MMP EXPRESSION AS DETERMINED BY IMMUNOHISTOCHEMISTRY To compare expression of collagenase- 3 and its activator MT1-MMP in squamous cell carcinomas of the oesophagus and to identify the location of cells expressing these enzymes, we used immunohistochemistry. Of the 35 samples of oesophageal carcinoma, $30(85.7 \%)$ were positive for collagenase-3. Among the collagenase- 3 positive cases, the enzyme was predominantly expressed in tumour cells in 27 samples $(90.0 \%)$ and weakly expressed in stromal cells in the other three samples. In contrast, MT1-MMP was present in 28 $(80.0 \%)$ of 35 tumour samples. Among the MT1-MMP positive cases, the enzyme was predominantly expressed in tumour cells in 22 samples $(78.6 \%)$ and mainly in stromal cells in the other six samples $(21.4 \%)$. As shown in fig 4 , intense collagenase- 3 immunoreactivity was detected in the cytoplasm of tumour cells, especially along the invading front of the carcinoma (fig. 4A), but not in normal mucosa (fig 4D). Interestingly, a parallel section of this tumour was positive for MT1-MMP in the same collagenase- 3 positive carcinoma tissues (fig 4B) but not in normal mucosa (fig 4E). Twenty seven cases $(77.1 \%)$ were positive for both collagenase-3 and MT1-MMP expression 

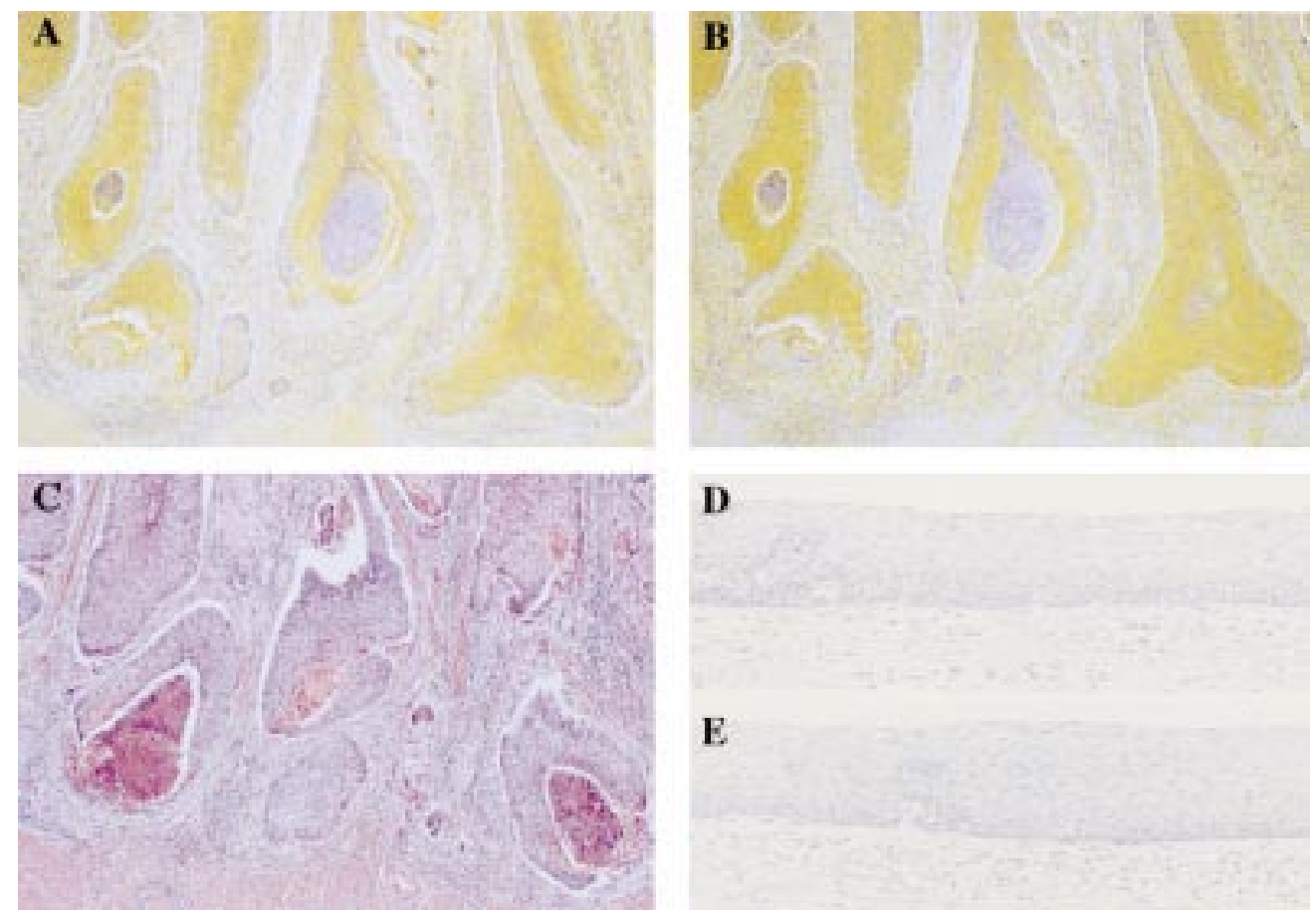

Figure 4 Immunohistochemical staining for collagenase-3 $(A, D)$ and $M T 1-M M P(B, E)$ in human oesophageal carcinoma. (A) Collagenese-3 was strongly expressed in tumour cells, especially at the invasive front of the tumour cells. Also, weak expression was detected in stromal fibroblasts surrounding the tumour cells. (B) In a parallel section,

$M T 1-M M P$ was detected mainly in tumour cells and weakly expressed in stromal fibroblasts surrounding the tumour cells. Also, MT1-MMP was detected in the same collagenase-3 positive tumour cells. (C) Haematoxylin-eosin staining in a parallel section. $(D, E)$ Neither collagenase-3 nor MT1-MMP was expressed in normal tissues. Original magnification $\times 100$.

in tumour tissues. A significant association between collagenase-3 and MT1-MMP expression in tumour tissues was demonstrated (table 2).

A total of 20 of 22 patients (91\%) with a $\mathrm{T} / \mathrm{N}$ ratio $>3.5$ for collagenase- $3 \mathrm{mRNA}$ expression had positive immunohistochemical staining for collagenase- 3 in tumour tissues, and 16 of 21 patients $(76.2 \%)$ with a $\mathrm{T} / \mathrm{N}$ ratio $>2.1$ for MT1-MMP mRNA expression had positive immunohistochemical staining for MT1MMP in tumour tissues.

SURVIVAL ANALYSIS

Median survival in the high collagenase-3 group ( $\mathrm{T} / \mathrm{N}$ relative ratio $>3.5$ ) was 14.4 months. The difference in survival time was significant between the high collagenase- 3 mRNA expression group and the low collagenase- 3 mRNA expression group $(\mathrm{p}<0.05$, Mantel-Cox method) (fig 5). In contrast, there was no significant correlation between levels of MT1MMP mRNA expression and survival time.

In a multivariate analysis subsequently performed with the Cox's proportional hazard model, parameters included vascular involvement, lymph node metastasis, clinical stage,

Table 2 Correlation between collagenase- 3 and MT1-MMP expression in tumour tissues by immunohistochemistry

\begin{tabular}{lccc}
\hline & \multicolumn{2}{c}{ Collagenase-3 expression } & \\
\cline { 2 - 3 } & Positive & Negative & p Value \\
\hline MT1-MMP expression & & & \\
Positive & $27(77.1 \%)$ & $1(2.9 \%)$ & $<0.05$ \\
Negative & $3(8.6 \%)$ & $4(11.4 \%)$ & \\
\hline
\end{tabular}

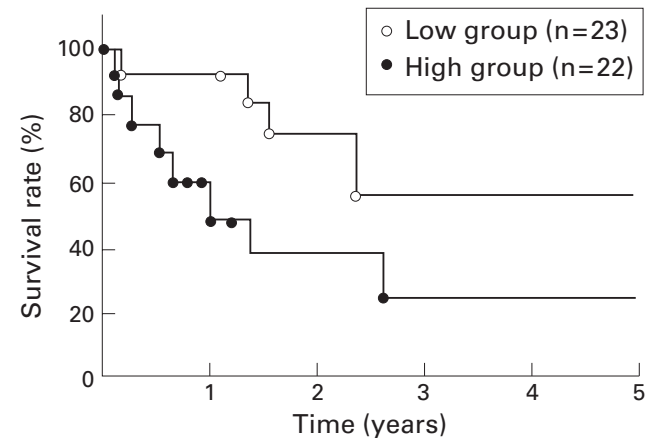

Figure 5 Survival curve for 45 patients with oesophageal cancer with respect to $m R N A$ expression of collagenase-3. Patients with high collagenase-3 (MMP-13) expression (high group; tumour/normal $(T / N)$ ratio $>3.5$ ) exhibited a significantly poorer prognosis than the low collagenase group $(T / N \leqslant 3.5)(p<0.05)$.

and collagenase-3 and MT1-MMP mRNA expression. The survival analyses demonstrated that high collagenase- 3 mRNA expression was an independent prognostic factor (hazard ratio $2.84,95 \%$ confidence interval (CI) 1.22-3.83), and high MT1-MMP mRNA expression was not (hazard ratio 1.95, 95\% CI 1.01-2.98). Lymph node metastasis was also a significant determinant of prognosis (hazard ratio 3.85 , 95\% CI $1.45-7.32$ ) but the remaining parameters were not independent prognostic factors in our study.

\section{Discussion}

Degradation and remodelling of the surrounding basement membrane and extracellular matrix are crucial events in tumour invasion. ${ }^{6}$ In general, coexpression of several MMPs is 
characteristic of human carcinomas which means that synergistic actions of different proteases produced either by stromal or tumour cells are involved. Collagenolytic enzymes, including MMP-1 and MMP-8 in malignant tumours, are known to be produced not only by tumour cells but also by a variety of host cells such as fibroblasts, endothelial cells, and macrophages that interact with the tumours. With respect to collagenase- 3 , we noted that its expression at the protein and mRNA levels was detected in most oesophageal tumours but not in intact oesophageal mucosa. Recently, Johansson et al reported that collagenase-3 mRNA was detected in tumour cells using in situ hybridisation methods but signals were negative in stromal cells in squamous cell carcinoma of the head and neck. ${ }^{10}$ In our study, immunohistochemical detection of collagenase-3 was localised predominantly in tumour cells at the invading periphery of the tumour in contrast with stromal cells, and there was a correlation between mRNA levels and vascular involvement, lymph node metastasis, or tumour staging. Also, there were close associations between collagenase- 3 mRNA expression, protein expression, and gelatinolytic activity in each case. We noted that collagenase- 3 expression in tumour cells was highly correlated with the invasiveness of the tumour to the surrounding tissues. The substrate specificity of collagenase- 3 is similar to that of gelatinase (MMP-2 or MMP-9), and collagenase- 3 cleaves gelatin as well as types 1 , 2 , and 3 collagens and other extracellular matrix components. Therefore, one reason for tumour aggressiveness in patients with high collagenase- 3 activity may be that this enzyme can widely degrade components of the basement membrane and connective tissue surrounding tumour cells, as shown by gelatin zymography.

The prognosis and choice of therapy for patients with oesophageal carcinoma are based on both histological type and tumour stage. ${ }^{27}$ MMPs are associated with the prognosis of patients with different malignancies. ${ }^{17-20} 232829$ With respect to oesophageal carcinoma, it has been reported that the presence of MMP-1, determined by immunohistochemistry, was associated with a poor prognosis, unlike MMP-2 or MMP-9. ${ }^{23}$ In the present study, we followed patients and recorded whether a higher collagenase-3 mRNA level predicted recurrence. We found that the prognosis of patients was significantly associated with collagenase-3 mRNA expression and that it was an independent prognostic factor, following lymph node metastasis, in multivariate analyses. However, this result is preliminary because of the small sample size and should be verified in a larger number of cases.

The mechanism involved in collagenase- 3 activation is complex. It has been observed that collagenase- 3 expression is enhanced by cytokines, such as transforming growth factoralpha and -beta, and tumour necrosis factor-alpha. ${ }^{10}$ In a recent report gelatinase $\mathrm{A}$ (MMP-2) and membrane-type metalloproteinase (MT1-MMP) were found to process collagenase-3, and the activation rate of collagenase- 3 by MT1-MMP was enhanced in the presence of a latent form of MMP-2. ${ }^{15} 16$ With regard to MMP-1, among the collagenase subfamily including collagenase-3, there is no evidence of MMP-1 activation by MT1-MMP.

In our study there were two bands $(72 \mathrm{kDa}$ and $41 \mathrm{kDa}$ ) considered to correspond to the latent and active forms of MMP-2. ${ }^{30}{ }^{31}$ Immunohistochemical studies reported the presence of MMP-2 in the majority of oesophageal carcinomas. ${ }^{21}$ Some workers noted a good correlation between MT1-MMP expression and activation of MMP-2 in clinical samples such as lung carcinoma, ${ }^{30}$ malignant brain tumours, ${ }^{32}$ and gastric carcinoma. ${ }^{19}$ But we found no prior documentation of a correlation between MT1MMP expression and collagenase- 3 expression, especially in oesophageal carcinoma. Therefore, on the basis of in vitro data, we investigated collagenase-3 and MT1-MMP expression in oesophageal carcinoma to determine any correlation between these enzymes. Our present study revealed that there was a significant correlation between MT1-MMP and collagenase-3 mRNA expression in clinical samples of human oesophageal carcinoma, as shown in fig 2 . Interestingly, the distribution of MT1-MMP expression was similar to that of collagenase- 3 in most tumour cells and there was a significant association between collagenase-3 and MT1MMP expression, as determined by immunohistochemistry. These results suggest that the production and release of collagenase- 3 from the tumour cell-host tissue interaction may be linked to expression of MT1-MMP produced mainly by the tumour cells. Some investigators reported that collagenase-3 derived from tumour cells may be activated by stromal cells because both MMP-2 and MT1-MMP are confined to the stroma. ${ }^{33}$ In contrast, our results suggest that MT1-MMP may be linked to expression of collagenase- 3 by tumour cells mainly in an autocrine manner as the majority of tumour cells themselves produce both collagenase- 3 and its activator MT1-MMP. In summary, these observations lend support to the hypothesis that MMP expression in tumours versus stroma may be controlled, at least in part, by tissue specific mechanisms, and the breakdown of the extracellular matrix surrounding invasive tumours may not depend on expression of a single MMP but involve interactions between tumour and stromal cells, including activation of tumour cell derived MMP by tumour cells themselves and/or stromal cells.

In conclusion, collagenase- 3 expression may influence the prognosis of subjects with oesophageal carcinoma through tumour cell invasion, vascular involvement, and lymph node metastasis. Consistent with these data, the presence of collagenase- 3 was associated with a particularly poor prognosis. Thus these observations suggest that the ability of collagenase- 3 to initiate and continue degradation of fibrillar collagens makes it a powerful proteolytic tool for cancer cells and may contribute to their invasive potency in association with MT1-MMP. Finally, it is hoped that identification of individual MMPs, including 
collagenase- 3 , and regulation of activation systems associated with MT1-MMP in oesophageal carcinoma may provide benefits in establishing novel therapeutic strategies for preventing invasion and metastasis of these tumour cells.

Our study has demonstrated the clinical significance of expression of collagenase- 3 and MT1-MMP in tumour tissue. In the near future we hope to be able to predict the aggressive behaviour of oesophageal carcinomas using a preoperative sample, such as a biopsy specimen; this would be useful in a clinical setting. Further investigation is warranted using a larger series.

We thank Dr Tanaka (Department of Surgery, Saitama Cancer Center) for support and Dr Akazawa (Department of Medical Informatics, Niigata University) for advice on statistical analysis. We also thank Ms Miyake for excellent technical assistance.

1 Sugimachi K, Matsuoka H, Ohno S, et al. Multivariate approach for assessing the prognosis of clinical oesophageal carcinoma. Br 7 Surg 1988;75:1115-18.

2 Isono $K$, Sato $H$, Nakayama $K$. Results of a nationwide study on the three-field lymph node dissection of esophageal cancer. Oncology 1991; 48:411-20.

3 Davies B, Waxman J, Wasan $\mathrm{H}$, et al. Levels of matrix metalloproteases in bladder cancer correlate with tumor grade and invasion. Cancer Res 1993;53:5365-9.

4 Mori M, Barnard GF, Mimori K, et al. Overexpression of matrix metalloproteinase-7 mRNA in human colon carcimatrix metalloproteinase-7 mRNA

5 Sato H, Takino T, Okada Y, et al. A matrix metalloproteinase expressed on the surface of invasive tumour cells Nature 1994;370:61-5.

6 MacDougall JR, Matrisian LM. Contributions of tumour and stromal matrix metalloproteinases to tumour progression, invasion and metastasis. Cancer Metastasis Rev 1995;14:351-62.

7 Birkedal HH. Proteolytic remodeling of extracellular matrix. Curr Opin Cell Biol 1995;7:728-35.

8 Birkedal HH, Moore WG, Bodden MK, et al. Matrix metalloproteinases: a review. Crit Rev Oral Biol Med 1993, 4:197-250.

9 Freije JM, Diez II, Balbin M, et al. Molecular cloning and expression of collagenase-3, a novel human matrix metalloproteinase produced by breast carcinomas. $f$ Biol Chem proteinase produced

10 Johansson N, Airola K, Grenman R, et al. Expression of collagenase-3 (matrix metalloproteinase-13) in squamous cell carcinomas of

11 Uria JA, Balbin M, Lopez JM, et al. Collagenase-3 (MMP13) expression in chondrosarcoma cells and its regulation by basic fibroblast growth factor. Am F Pathol 1998;153:91101 .

12 Uitto VJ, Airola K, Vaalamo M, et al. Collagenase-3 (matrix metalloproteinase-13) expression is induced in oral mucosal epithelium during chronic inflammation. Am f Pathol 1998;152:1489-99.

13 Johansson N, Saarialho KU, Airola K, et al. Collagenase-3 (MMP-13) is expressed by hypertrophic chondrocytes, periosteal cells, and osteoblasts during human fetal bone development. Dev Dyn 1997;208:387-97.

14 Wernicke D, Seyfert C, Hinzmann B, et al. Cloning of collagenase 3 from the synovial membrane and its expression in rheumatoid arthritis and osteoarthritis. 7 Rheumatol 1996;23:590-5.

15 Knauper V, Will H, Lopez OC, et al. Cellular mechanisms for human procollagenase-3 (MMP-13) activation. Evidence that MT1-MMP (MMP-14) and gelatinase A MMP-2) are able to generate active enzyme. $f$ Biol Chem 1996;271:17124-31.

16 Cowell S, Knauper V, Stewart ML, et al. Induction of matrix metalloproteinase activation cascades based on membranetype 1 matrix metalloproteinase: associated activation of gelatinase A, gelatinase B and collagenase 3. Biochem 7 1998;15:453-8.

17 Haupt LM, Thompson EW, Griffiths LR, Irving MG. IS-RT-PCR assay detection of MT-MMP in a human breast cancer cell line. Biochem Mol Biol Int 1996;39:55361.

18 Sato H, Okada Y, Seiki M. Membrane-type matrix metalloproteinases (MT-MMPs) in cell invasion. Thromb Haemost 1997; 78:497-500.

19 Mori M, Mimori K, Shiraishi T, et al. Analysis of MT1-MMP and MMP2 expression in human gastric cancers. Int f Cancer 1997; 74:316-21.

20 Caenazzo C, Onisto M, Sartor L, et al. Augmented membrane type 1 matrix metalloproteinase (MT1-MMP): MMP-2 messenger RNA ratio in gastric carcinomas with poor prognosis. Clin Cancer Res 1998;4:2179-86.

21 Shima I, Sasaguri Y, Kusukawa J, et al. Production of matrix metalloproteinase-2 and metalloproteinase-3 related to malignant behavior of esophageal carcinoma. A clinicopathologic study. Cancer 1992;70:2747-53.

22 Otani Y, Okazaki I, Arai M, et al. Gene expression of interstitial collagenase (matrix metalloproteinase 1) in gastrointestinal tract cancers. F Gastroenterol 1994;29:391-7.

23 Murray GI, Duncan ME, O'Neil P, et al. Matrix metalloproteinase-1 is associated with poor prognosis in oesophageal cancer. F Pathol 1998;185:256-61.

24 Mori M, Barnard GF, Staniunas RJ, et al. Prothymosinalpha mRNA expression correlates with that of c-myc in human colon cancer. Oncogene 1993;8:2821-6.

25 Sato Y, Mukai K, Furuya S, et al. The AMeX method: a multipurpose tissue-processing and paraffin-embedding method. Extraction of protein and application to immunoblotting. Am f Pathol 1992;140:775-9.

26 Japanese Society of Esophageal Disease. Guide lines for the clinical and pathologic studies on carcinoma of the esophagus. Fpn $\mathcal{F}$ Surg 1992;8:24-48.

27 Earlam R, Cunha MJ. Oesophageal squamous cell carcinoma: I. A critical review of surgery. $\mathrm{Br} \mathcal{F}$ Surg 1980;67:381-90.

28 Yamashita K, Azumano I, Mai M, et al. Expression and tissue localization of matrix metalloproteinase 7 (matrilysin) in human gastric carcinomas. Implications for vessel invasion and metastasis. Int $\mathcal{F}$ Cancer 1998;79:187-94.

29 Kanayama H, Yokota K, Kurokawa Y, et al. Prognostic values of matrix metalloproteinase-2 and tissue inhibitor of metalloproteinase-2 expression in bladder cancer. Cancer 1998;82:1359-66.

30 Tokuraku M, Sato H, Murakami S, et al. Activation of the precursor of gelatinase $\mathrm{A} / 72 \mathrm{kDa}$ type IV collagenase/ MMP-2 in lung carcinomas correlates with the expression of membrane-type matrix metalloproteinase (MT-MMP) and with lymph node metastasis. Int f Cancer 1995;64:3559 .

31 Miyazaki K, Umenishi F, Funahashi K, et al. Activation of TIMP-2/progelatinase A complex by stromelysin. Biochem Biophys Res Commun 1992:185:852-9.

32 Yamamoto M, Mohanam S, Sawaya R, et al. Differential expression of membrane-type matrix metalloproteinase and its correlation with gelatinase $\mathrm{A}$ activation in human malignant brain tumors in vivo and in vitro. Cancer Res 1996;56:384-92.

33 Okada A, Bellocq JP, Rouyer N, et al. Membrane-type matrix metalloproteinase (MT-MMP) gene is expressed in stromal cells of human colon, breast, and head and neck carcinomas. Proc Natl Acad Sci USA 1995;92:2730-4. 